Taylor, P. D., T. L. Crewe, S. A. Mackenzie, D. Lepage, Y. Aubry, Z. Crysler, G. Finney, C. M. Francis, C. G. Guglielmo, D. J. Hamilton, R. L. Holberton, P. H. Loring, G. W. Mitchell, D. Norris, J. Paquet, R. A. Ronconi, J. Smetzer, P. A. Smith, L. J. Welch, and B. K. Woodworth. 2017. The Motus Wildlife Tracking System: a collaborative research network to enhance the understanding of wildife movement. Avian Conservation and Ecology 12(1):8. https://doi.org/10.5751/ACE-00953-120108

Copyright $(2017$ by the author(s). Published here under license by the Resilience Alliance.

Methodology

\title{
The Motus Wildlife Tracking System: a collaborative research network to enhance the understanding of wildlife movement
}

Philip D. Taylor ${ }^{1,2}$, Tara L. Crewe ${ }^{2,3}$, Stuart A. Mackenzie ${ }^{2}$, Denis Lepage $^{2}$, Yves Aubry ${ }^{4}$, Zoe Crysler $^{1,2}$, George Finney ${ }^{2}$, Charles M. Francis $^{5}$, Christopher G. Guglielmo ${ }^{6}$, Diana J. Hamilton ${ }^{7}$, Rebecca L. Holberton ${ }^{8}$, Pamela H. Loring ${ }^{9,10}$, Greg W. Mitchell ${ }^{11}$, D. Ryan Norris $^{12}$, Julie Paquet ${ }^{13}$, Robert A. Ronconi ${ }^{1,14}$, Jennifer R. Smetzer ${ }^{9}$, Paul A. Smith ${ }^{11}$, Linda J. Welch ${ }^{15}$ and Bradley K. Woodworth 1,12

${ }^{1}$ Biology Department, Acadia University, Wolfville, Nova Scotia, Canada, ${ }^{2}$ Bird Studies Canada, Port Rowan, Ontario, Canada, ${ }^{3}$ Department of Biology, University of Western Ontario, London, Ontario, Canada, ${ }^{4}$ Canadian Wildlife Service, Environment and Climate Change Canada, Quebec, Quebec, Canada, ${ }^{5}$ Canadian Wildlife Service, Environment and Climate Change Canada, Ottawa, Ontario, Canada, ${ }^{6}$ Department of Biology, Advanced Facility for Avian Research, University of Western Ontario, London, Ontario, Canada, ${ }^{7}$ Department of Biology, Mount Allison University, Sackville, New Brunswick, Canada, ${ }^{8}$ Lab of Avian Biology, University of Maine, Orono, Maine, USA, ${ }^{9}$ Department of Environmental Conservation, University of Massachusetts Amherst, Massachusetts, USA, ${ }^{10}$ United States Fish and Wildlife Service, Division of Migratory Birds, Northeast Region, Hadley, Massachusetts, USA, ${ }^{11}$ Wildlife Research Division, Environment and Climate Change Canada, Ottawa, Ontario, Canada, ${ }^{12}$ Department of Integrative Biology, University of Guelph, Guelph, Ontario, Canada, ${ }^{13}$ Canadian Wildlife Service, Environment and Climate Change Canada, Sackville, New Brunswick, Canada, ${ }^{14}$ Canadian Wildlife Service, Environment and Climate Change Canada, Dartmouth, Nova Scotia, Canada, ${ }^{15}$ United States Fish and Wildlife Service, Maine Coastal Islands NWR, Milbridge, Maine

ABSTRACT. We describe a new collaborative network, the Motus Wildlife Tracking System (Motus; https://motus.org), which is an international network of researchers using coordinated automated radio-telemetry arrays to study movements of small flying organisms including birds, bats, and insects, at local, regional, and hemispheric scales. Radio-telemetry has been a cornerstone of tracking studies for over 50 years, and because of current limitations of geographic positioning systems (GPS) and satellite transmitters, has remained the primary means to track movements of small animals with high temporal and spatial precision. Automated receivers, along with recent miniaturization and digital coding of tags, have further improved the utility of radio-telemetry by allowing many individuals to be tracked continuously and simultaneously across broad landscapes. Motus is novel among automated arrays in that collaborators employ a single radio frequency across receiving stations over a broad geographic scale, allowing individuals to be detected at sites maintained by others. Motus also coordinates, disseminates, and archives detections and associated metadata in a central repository. Combined with the ability to track many individuals simultaneously, Motus has expanded the scope and spatial scale of research questions that can be addressed using radio-telemetry from local to regional and even hemispheric scales. Since its inception in 2012 , more than 9000 individuals of over 87 species of birds, bats, and insects have been tracked, resulting in more than 250 million detections. This rich and comprehensive dataset includes detections of individuals during all phases of the annual cycle (breeding, migration, and nonbreeding), and at a variety of spatial scales, resulting in novel insights into the movement behavior of small flying animals. The value of the Motus network will grow as spatial coverage of stations and number of partners and collaborators increases. With continued expansion and support, Motus can provide a framework for global collaboration, and a coordinated approach to solving some of the most complex problems in movement biology and ecology.

\section{Le Système de suivi de la faune Motus : un réseau de recherche collaboratif visant à mieux comprendre le déplacement des animaux}

RÉSUMÉ. Le Système de suivi de la faune Motus (Motus; https://motus.org), un nouveau réseau collaboratif de chercheurs internationaux, repose sur un ensemble coordonné de stations automatisées de radiotélémétrie pour étudier le déplacement de petits organismes volant, comme les oiseaux, les chauves-souris et les insectes, aux échelles locales et régionales, et à celle de l'hémisphère. Pierre angulaire pour les études de suivi depuis plus de 50 ans, la radiotélémétrie est encore le principal moyen de suivre le déplacement de petits animaux avec une grande précision temporelle et spatiale, en raison des limites que présentent les émetteurs basés sur le système de positionnement géographique (GPS) ou satellite. Des stations réceptrices automatisées, de pair avec la récente miniaturisation et le codage digital des émetteurs, sont derrière l'utilité accrue de la radiotélémétrie, qui permet désormais de suivre constamment et simultanément de nombreux individus sur de vastes territoires. Parmi les dispositifs automatisés, Motus est novateur car il permet aux collaborateurs l'emploi d'une fréquence radio unique pour toutes les stations réceptrices installées sur le vaste territoire, chacun des 
individus suivis pouvant être détectés à des sites entretenus par d'autres collaborateurs. Motus coordonnent, disséminent et archivent aussi les détections et les métadonnées associées dans un site central de stockage. Grâce à sa capacité de suivre un grand nombre d'individus simultanément, Motus a permis d'étendre la portée et l'échelle spatiale des questions scientifiques pouvant être résolues au moyen de la radiotélémétrie, de l'échelle locale à régionale, et même à celle de l'hémisphère. Depuis sa création en 2012 , plus de 9000 individus appartenant à de plus de 87 espèces d'oiseaux, de chauves-souris et d'insectes ont été suivis, fournissant plus de 250 millions de détections. Ce jeu de données, riche et détaillé, comprend des détections d'individus à toutes les étapes du cycle annuel (nidification, migration et hors nidification) et à une variété d'échelles spatiales, menant à des découvertes sur le comportement de déplacement de petits animaux volant. Le réseau Motus prendra encore plus de valeur au fur et à mesure que la couverture spatiale des stations et le nombre de partenaires et de collaborateurs augmenteront. En raison de l'expansion et de l'appui continu reçu, Motus peut fournir un cadre de travail pour la collaboration globale et une approche coordonnée dans la résolution de quelques-uns des problèmes les plus complexes en biologie et écologie du déplacement.

Key Words: automated radio-telemetry; behavior; full life-cycle biology; migration; migratory connectivity; movement biology; movement ecology; stopover

\section{TRACKING WILDLIFE MOVEMENT}

Declines in populations of many species of birds, bats, and insects have emphasized the need for an improved understanding of the factors that limit and regulate populations, particularly in the face of a rapidly changing landscape and climate. For migratory species, a key element to identifying limiting factors and planning conservation is understanding their movement patterns, including migratory connectivity - the links between habitat used at different times of year, including breeding territories, migratory stopover sites, and wintering areas (Marra et al. 2011). Advances in tracking technologies continue to allow researchers to track smaller animals with greater temporal and geographic precision than ever before, which is revolutionizing our understanding of the movements of organisms and the factors that influence movement and survival during all phases of their life cycle (Fraser et al. 2012, Kays et al. 2015).

Many limitations and trade-offs still exist in the use of current tracking technologies, particularly for small animals $(<50 \mathrm{~g})$, which comprise the vast majority of biodiversity (Bridge et al. 2011, Kays et al. 2015). Long-distance movements have generally been tracked with either satellite tags or with various types of data loggers. The smallest tags currently available that can be detected by satellite, using Geographic Positioning System (GPS) to determine locations, still weigh $3.5 \mathrm{~g}$, which is too heavy for most animals $<100$ g. Data loggers including GPS provide accurate position estimates ( $\pm 30 \mathrm{~m}$ or better) and have been used to track individuals throughout their entire annual cycle, delineate migratory connectivity, and estimate home range centers on breeding and wintering grounds (Hallworth and Marra 2015). However, because of power needs, temporal resolution must be compromised to extend battery life, and the mass of the smallest units is near $1 \mathrm{~g}$, too large to place on most small animals. Data loggers using light-level geolocators (GLS) can weigh as little as $0.3 \mathrm{~g}$ and have provided much novel information on migratory connectivity for small songbirds and shorebirds, but such devices have relatively low location accuracy (at best $\pm 50-100 \mathrm{~km}$ ) particularly near the equinox when many temperate species migrate (Fudickar et al. 2012, McKinnon et al. 2013, Rakhimberdiev et al. 2016), or in polar environments where there is continuous light or darkness. Individuals carrying either of these types of tags also need to be recaptured to retrieve location data, which limits their use to species with high breeding or wintering site fidelity. Importantly, only surviving and returning individuals can be recaptured for data retrieval and this is a problematic bias for studies of movement ecology.

Radio-telemetry has been used to track wildlife movements for over 50 years (Adams 1965, Cochran et al. 1965). For many small organisms, e.g., small reptiles, amphibians, insects, bats and birds, radio-telemetry remains a viable method to track local and regional movements with a high degree of temporal and spatial precision, without the need to recapture individuals or remotely download data from tags (Cagnacci et al. 2010, Bridge et al. 2011, Kays et al. 2015). Tags can be very small and light $(<0.21 \mathrm{~g})$, and pulse frequency (typically 2-10 times per minute) provides high temporal accuracy, which is useful for categorizing behavioral states (movement, resting, flights). However, in traditional radiotelemetry, the need to manually detect tagged animals, either by foot, car, or plane, requires a large amount of effort by field personnel, placing limits on the number of individuals that can be tracked, the number and time span of detections that can be collected (field staff cannot monitor continuously, 24 hours a day), and on the spatial scale that can be sampled. Human presence while tracking can also alter the natural behavior of the tracked animal. This results in limited and potentially biased information on the activity and movement patterns of individuals and populations.

Recent advances in miniaturization of electronics and computers have led to broader use of automated radio-telemetry systems (Cochran et al. 1965), which enable the continuous recording of tag signals from fixed position or mobile receivers and at times of the day or in weather conditions that otherwise limit traditional radio telemetry projects. Automated radio-telemetry systems such as the Automated Radio Telemetry System (ARTS; Kays et al. 2011), the Biological AutomAted RAdiotelemetry System (BAARA; К̌eřucha et al. 2015), the Advanced Tracking and Localization of Animals in real-life Systems (http://move-ecolminerva.huji.ac.il), and the Quail Ridge Automated Animal Tracking System (http://qraat.ucdavis.edu) are typically employed at local (Goymann et al. 2010, Ward et al. 2014, Louder et al. 2015) or regional spatial scales (Mills et al. 2011, Taylor et al. 2011, Deppe et al. 2015). These can provide moderately accurate positional data $( \pm \sim 1-15 \mathrm{~km})$, limited primarily by the situation of receiving stations and the strength of the signal emitted by the tag. In cases where tagged animals are easily approached, supplementary hand-held radio tracking can allow for position accuracy of $<5 \mathrm{~m}$. 
Fig. 1. Locations of Motus receiving stations in the Western Hemisphere between 2014 and 2016. Stations deployed in Europe are not shown. Permanent (active through most of the year) stations are shown by open circles, while stations that were set up temporarily for research-specific needs are shown by $\times$. Insets show the location of towers in the grid array in Ontario (A), and the turnstile or "fence" style of array along the coast of northeastern North America (B), which has been used to detect tagged migrants as they depart over the ocean during migration, coming onto land after a flight, or flying down the coast.

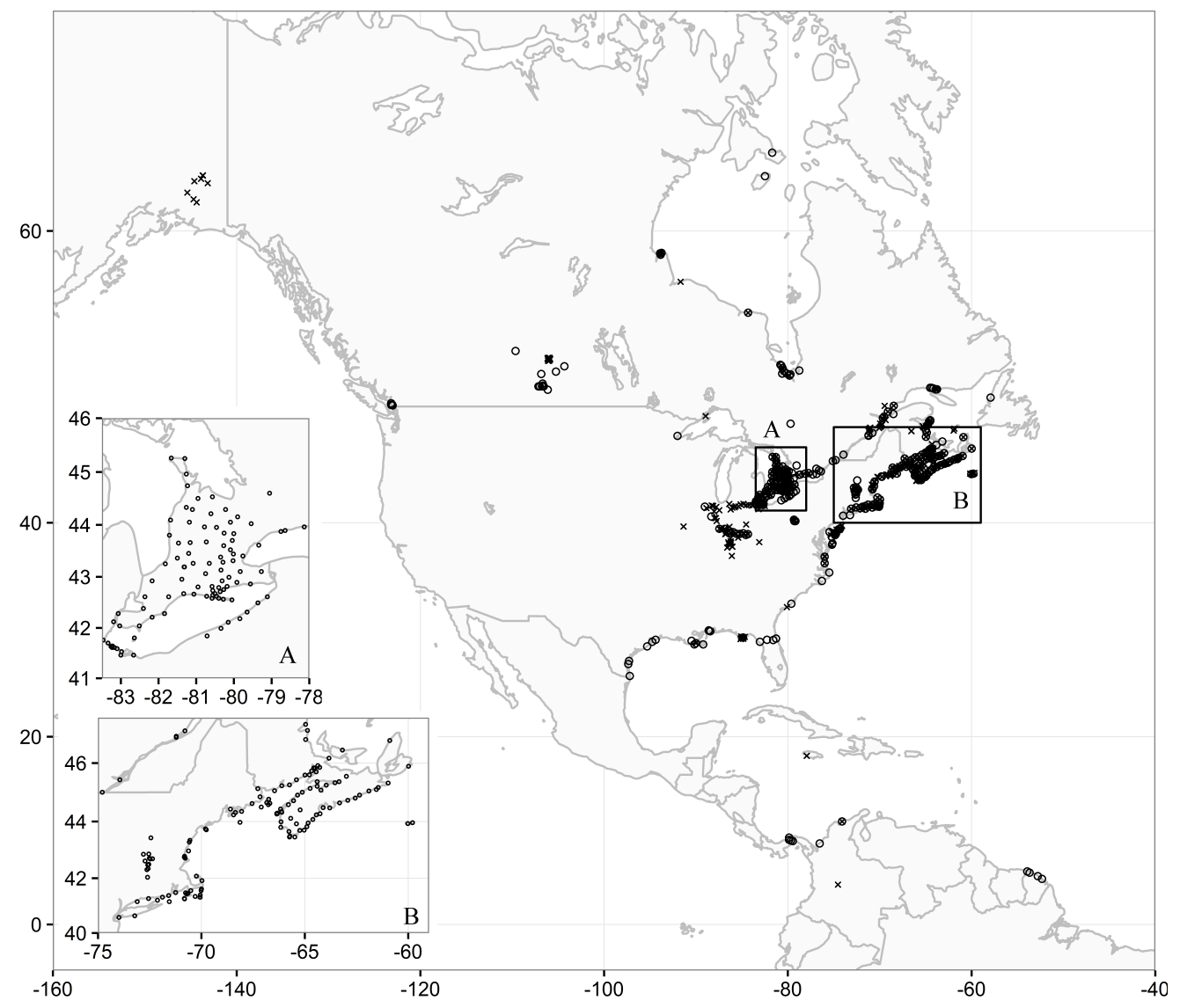

We introduce the Motus Wildlife Tracking System (hereafter "Motus"; https://motus.org), a continental scale tracking network. Initially inspired by the Ocean Tracking Network (http:// oceantrackingnetwork.org), Motus is unique among the automated radio telemetry systems described above in that it functions as a network of collaborating researchers and organizations managing independent arrays of receiving towers over a relatively large spatial extent. All data is processed through a centralized database, and digitally coded tags allow many thousands of individuals to be tracked simultaneously on a single frequency, which allows detection of tags by any receiver in the network. Because receivers are listening continuously on a single frequency (as opposed to cycling through many possible frequencies), the probability of detecting any given tag in the vicinity of a receiver is vastly improved over traditional, nonautomated methods.

The conceptual framework behind Motus expands the scope and spatial scale of research and conservation questions that can be addressed compared to traditional radio-telemetry and other tracking technologies, particularly for small animals that cannot currently be tracked using GPS loggers, or for studies that require high temporal resolution. In this paper, we describe the physical and database infrastructure behind Motus, summarize novel advancements that have been made in movement ecology as a result of this effort, and discuss potential future applications in light of the expected continued growth of the network and rapid advances in technology.

\section{THE MOTUS NETWORK}

Motus has its roots in an automated radio-telemetry network developed at Acadia University and implemented at a regional scale with numerous partners in northeastern North America in 2012-2013. This network was inspired by development of the relatively low-cost Sensorgnome receiver (https://sensorgnome. org), described below. In 2014, with funding and support from a Canadian Foundation for Innovation grant, Motus was 
developed as a program of Bird Studies Canada, in partnership with Acadia University, Western University, the University of Guelph, and other collaborating researchers and organizations. By the end of 2016, Motus had expanded to include more than 120 independent research projects, and comprised over 325 active receiver stations across 11 countries and 3 continents (Fig. 1). We anticipate it will continue to expand.

\section{Tags (transmitting device)}

To date, most tags used in the Motus system have been coded "nanotags" manufactured by Lotek Wireless (Newmarket, Ontario: http://lotek.com). These tags range in mass from $\sim 0.2$ to $2.6 \mathrm{~g}$ and have an estimated lifespan of between 10 days and 3 years, depending on battery size (smaller batteries have shorter lifespans) and how often the radio transmission is emitted. When activated, each tag emits a very rapid series of radio transmissions (pulses) with a coded sequence, repeated at fixed intervals (burst rate). The combination of sequence code and burst rate is used to uniquely identify individual tags. More rapid burst rates result in higher power consumption and shorter lifespans, but also increase detection and recognition probabilities. This means that researchers must choose burst rates and tag sizes, trading off the length of time an animal is tracked with temporal resolution, and therefore detectability.

Motus can also accommodate other types of tags, provided they operate on the same frequency. This can be useful for projects in which the primary goal is not necessarily spatial tracking, for example measuring temperature variation in sedentary animals (McGuire et al. 2012, 2014). The use of noncoded tags in the broader Motus network is somewhat limited because only a small number of such tags can be uniquely defined for any given frequency (by changing the timing between or length of pulses). In principle, any tag that uses some form of "on-off" radio pattern can be employed within Motus. However, where signal characteristics overlap across individuals, they cannot be uniquely identified and this can complicate tracking of movements over large spatial scales.

Prior to tag deployment, researchers "register" tags with Motus by submitting a recording of the tag signal, obtained using a compatible receiver. Recordings allow for a measure of the pattern of the coded signal (to $1 \mathrm{~ms}$ ), the exact burst rate, and other signal characteristics from which a unique ID is derived. This ensures that a record of specific tag characteristics is stored in the database, and that no conflicts exist with other tags in the system. Current compatible tags use pulse-width modulated codes that accommodate over 500 unique coded IDs. Linking codes with unique burst rates (prime numbers at $0.1 \mathrm{~s}$ ) allows for tens of thousands of uniquely coded tags within the array at any one time, all transmitting on the same frequency. Having all tags transmitting on a single frequency eliminates the need for receivers to "listen" sequentially on multiple frequencies, which decreases the probability of detecting tags on any given frequency.

Once registered, tags are activated by the user and affixed to animals using glue, sutures, or a variety of harness designs (e.g., Rappole and Tipton 1991, Warnock and Warnock 1993, Hill et al. 1999, Naef-Daenzer 2007, Streby et al. 2015). Prior to deployment, additional information is collected about the animal (e.g., species, weight and other morphometric measurements, age, sex, presence of other identifying tags such as numbered bands) and submitted to the Motus database. Once activated, tags can be detected by any station throughout the network that is monitoring the appropriate frequency.

\section{Receiver stations}

A receiver station comprises a power source, a receiver, and one or more antennas tuned to a specific frequency (currently 166.380 $\mathrm{MHz}$ in the Western Hemisphere, and $150.100 \mathrm{MHz}$ in Europe). Compatible receivers currently include Sensorgnome receivers, a relatively low cost receiver that can be built using open-source software and off-the-shelf hardware, or Lotek SRX/DX series receivers. Most receivers are equipped with a high-accuracy GPS sensor that allows for precise time synchronization and geolocation of the receiver. The total costs for a receiver station varies depending on the number and type of antennas, whether existing infrastructure can be used to mount antennas, and the power source. Information about receiver deployments, including geographic coordinates, start and anticipated end date and time, and antenna configuration and orientation, is registered in the Motus database, and made available to all users.

Receivers can accommodate multiple antennas, which are mounted on nearby structures or self-standing towers. Anywhere from one to six antennas are typically mounted at a single station. Sensorgnome receivers monitor each antenna continuously using software-defined antenna-specific radio receivers, whereas Lotek receivers use an antenna switchbox to cycle sequentially among antennas based on user-defined criteria, which will decrease the probability of detecting a tag on a given antenna. For close-range tracking of individuals, short- to medium-range antennas with a broad beam, such as small omni-directional antennas $\left(360^{\circ}\right.$ detection radius with a range of up to $\sim 500 \mathrm{~m}$ ) or 3-5 element Yagi antennas (detection range $2-3 \mathrm{~km}$ ) tend to be more appropriate. For longer-range detection $(>3 \mathrm{~km})$, directional 9element Yagi antennas are more useful. Tagged individuals are regularly detected simultaneously by sensorgnome receivers greater than $20 \mathrm{~km}$ apart using 9-element Yagi antennas, which gives some indication of the normal range of the antenna $(\sim 15$ $\mathrm{km})$. Long-distance detections are most likely when birds are in flight, well above the ground, and in line of sight of the antenna, although many factors influence detection distance, including height and orientation of transmitting and receiving antennas, and landscape features including topography, habitat structure, and human-made structures. Interference created by electromagnetic disturbance such as transmitting cellular or other antenna (common in urban areas), or at times of the day when people (and electronic devices) are more active, may also decrease the effective detection distance of a station. Stations are placed to minimize this interference.

Stations can be connected directly to a main power source (which reduces cost and maintenance), or run from solar-powered deep cycle batteries. Sensorgnome receivers allow for a direct connection to the internet via Ethernet or cellular phone network, which can provide real-time data transfer to the Motus database. Data from unconnected stations need to be downloaded manually from the receiver. In both cases, data are stored locally until deleted by a user, for security. Motus encourages station managers to maintain active receivers year-round, although some projectspecific stations are activated over shorter time periods (see https://motus.org for additional information on station setup). 


\section{Network configuration}

Because of the collaborative nature of Motus, the placement and maintenance of receivers throughout the network is driven primarily by the independent goals of collaborators. A map of receiver stations active at any point in time is available at https:// motus.org. Although some of the expansion to date has been adhoc, Bird Studies Canada and other organizations are leading a coordinated effort to guide the placement of new stations and fill spatial gaps to maximize Motus users' ability to address broadscale research and conservation goals.

The configuration of project-specific arrays will depend on research goals. A single strategically placed station at a breeding or stopover site might be sufficient on its own to gather information on activity level, including diel activity, stopover duration, and arrival or departure timing of individuals within detection range. Strategic grids of stations are the most commonly used configuration by Motus collaborators. Grids with closely spaced stations are useful to detect local movements and activity levels, and grids with more distant stations are useful to detect movements across broader landscapes (Fig. 1, inset A). Turnstile or fence arrays consist of stations deployed in a line to detect migrants as they move past in latitude or longitude. These have proven effective for detecting migrants as they move past geographic funnels or bottlenecks, including the Gulf of Mexico coast, Gulf of Maine coast, the lower Great Lakes, and the Panama Canal (Fig. 1, inset B). Point-to-point arrays, with receivers or groups of receivers at well-known breeding, wintering, and stopover areas, are also useful for detecting migratory movements between specific geographic locations. These have proven very effective for shorebirds that stage over a discrete series of known geographic locations. For any species, the use of closely-spaced grids allows activity levels (e.g., stopover duration, departure timing, diel activity) and local- and broadscale movement parameters (e.g., migratory speed, timing, orientation) to be estimated. Transient receivers on moving/ floating platforms can capture movements of birds at sea (Crysler 2015, Loring 2016; Ronconi, Taylor, Crysler, et al., unpublished manuscript).

\section{Data flow}

Motus relies on a centralized database housed at Bird Studies Canada's national data center. All tag, station, project, and user metadata are submitted by users, archived in the database, and linked and managed through the Motus research platform (Fig. 2). All tag detection data collected at receiving stations are joined with the master tag and station metadata to produce a complete database of unique detections from each station. Station performance such as on/off cycles of receivers, GPS, or antenna are also compiled and summarized.

To detect tags, radio signals captured by the receivers are compared against the tag recordings submitted to Motus during tag registration. Minimal processing of raw detection data occurs prior to making data accessible to researchers (primarily removing detections that are outside of the deployment period for a specific tag). Once processed, the principal investigator(s) of each project can access a master project file that contains raw detection data including signal strength values, standard deviation in signal strength, and run length (number of continuous detections of a unique code by a receiver). Users are provided with all data necessary to run additional data filters, for example to look for false-positive detections, and to assess activity levels of birds based on variability in signal strength values over time. Metadata, e.g., geographic location and antenna orientation, are provided for all stations where a given tag was detected. The archiving of all movement data in this way facilitates retrospective, cross-project analyses. Motus encourages such data sharing to support broad research and conservation objectives, but principal investigators maintain control over detections of their tags, and can establish a data sharing level that controls the availability of detailed detection and associated metadata to third parties.

Fig. 2. Conceptual diagram of the flow of information and data through the Motus network. Researchers tag animals, which then have the potential to generate detection data throughout the array. Data are fed into the Motus database, and the web interface provides users with tools to access, summarize, and visualize their data, or the potential to access additional tools through alternative data portals such as Movebank and the Avian Knowledge Network. The interpretation of detection data can contribute to conservation science, policy, and management, and to public engagement and education.

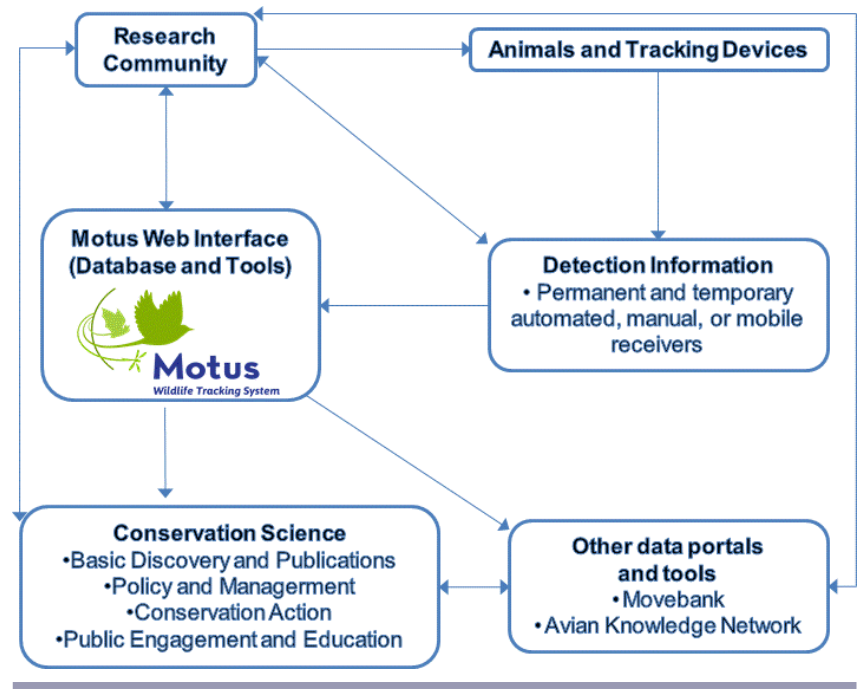

\section{CURRENT USES}

Since its inception in 2012, Motus collaborators have undertaken over 120 research projects, and tracked over 9000 individuals of 87 species across 9 avian orders (Procellariiformes, Falconiformes, Gruiformes, Charadriiformes, Cuculiformes, Strigiformes, Caprimulgiformes, Piciformes, and Passeriformes) comprising 25 avian families. Motus users have also tracked 9 species of insectivorous bats (family Vespertilionidae), and two families of large insects (Aeshnidae and Nymphalidae). Many of these projects would not have been possible with existing alternative tracking technologies, either because they did not offer sufficient temporal or spatial precision, the animals could not be recaptured, or the animals were too small to support larger tags.

Projects to date have logged over 250 million detections at over 560 receiving stations (Fig. 1) and, for many projects, a large 
portion of tagged animals (sometimes exceeding 80\%) are detected at stations beyond the original tagging site. This wealth of data has led to comprehensive and diverse applications in the study of breeding and postbreeding dispersal, stopover and migration behavior, and overwintering ecology. For example, detection data from Motus collaborators have been used to estimate stopover duration (Dossman et al. 2016, Mann et al. 2017, Neima 2017), activity level, e.g., onset of diel activity, stopover versus active migration (Crysler et al. 2016; Morbey et al., unpublished data), regional and site fidelity during migratory stopover (Mann et al. 2017, Neima 2017), precise departure and arrival times (Mitchell et al. 2015, Dossman et al. 2016, Müller et al. 2016), departure and flight orientation (Mitchell et al. 2015, Crysler et al. 2016, Kishkinev et al. 2016, Neima 2017), flight distance, time, and therefore flight speed (Woodworth et al. 2014, 2015, Brown and Taylor 2015, Mitchell et al. 2015, Crysler et al. 2016, Falconer et al. 2016), colony attendance patterns (Loring 2016), and types of movements, e.g., migratory, relocation (Woodworth et al. 2014, 2015, Crysler et al. 2016).

The ability to estimate these parameters has led to advancements in our understanding of the movement behavior of small animals, including the spatial and temporal scale of migratory stopover (Woodworth et al. 2015, Mann et al. 2017, Neima 2017), the influence of ecological barriers on movement behaviour (Woodworth et al. 2015, Crysler 2016, Dossman et al. 2016), postfledging dispersal movements (Brown and Taylor 2015, Crysler 2015), migratory connectivity (McKellar et al. 2015), the proximate mechanisms of orientation and navigation (Kishkinev et al. 2016), and effects of availability of roosting habitat on duration of stay (Mann et al. 2017). We have also gained understanding of how movements are influenced by intrinsic and extrinsic factors, including age (Brown and Taylor 2015, Mitchell et al. 2015, Crysler et al. 2016, Dossman et al. 2016, Kennedy et al. 2016), sex (Falconer et al. 2016), physiological condition (Dossman et al. 2016, Eikenaar et al. 2017), habitat (Woodworth et al. 2014), and weather (Mitchell et al. 2015, Dossman et al. 2016, Loring 2016, Neima 2017).

Motus is also providing collaborators with an opportunity to combine detection data from stations deployed internationally across a vast geographic area. Although many gaps in station coverage still exist, tagged individuals nevertheless have the potential to be detected over local, regional, and hemispheric spatial scales, and during all parts of their life cycle. One example is from a project tagging Swainson's Thrushes (Catharus ustulatus) and Gray-cheeked Thrushes (Catharus minimus) in the Andes and Sierra Nevada Mountains of Colombia in 2015 and 2016. Collaborative projects of Selva-Research for Conservation in the Neotropics, Environment and Climate Change Canada, Universidad de los Andes, University of Saskatchewan, Western University, University of Guelph, and Bird Studies Canada, have been examining local overwintering ecology (Andes), stopover behavior, and departure decisions (Sierra Nevada) of these species (Fig. 3; Gonzalez and Hobson, unpublished data). Battery life of the tags was between 180 to 320 days, which, in addition to providing local information on daily activity levels, stopover duration, and departure timing, also resulted in the opportunistic detection of many tagged individuals at northern stations while en-route to their breeding grounds, including by the turnstile "fences" in Indiana and along the Gulf of Mexico coast (Fig. 4).
These additional detections provided novel information on the exact time of passage past precise locations along their (previously unknown) migratory route (Fig. 5), and the first measurements of migratory speeds for these species over a broad spatial scale. This example demonstrates the potential of the Motus collaborative network to monitor local, regional, continental, and hemispheric scale movements, and argues strongly for its continued and strategic expansion to fill spatial gaps in coverage, particularly at key natural barriers that can funnel migrant passage.

Fig. 3. Raw signal strength $(\mathrm{dB})$ data for a radio-tagged Swainson's Thrush (Catharus ustulatus) detected on three antennas (A.1, oriented $270^{\circ}$; A.2, oriented $150^{\circ}$; and A.3, oriented $0^{\circ}$ ) on a Motus station deployed in the Andes, Colombia in 2016 (Figure 4, site A; Gonzalez and Hobson, unpublished data). After it was tagged on 16 March, this individual remained at the overwintering site until its departure on 29 April 2016. Patterns in signal strength variation during overwintering suggest greater activity levels during the day (higher variation), and reduced activity at night (lower variation; left panels). The right panels show signal strength data immediately before and during departure on 29 April, which shows a period of inactivity followed by departure from the site at approximately 23:40 (GMT).
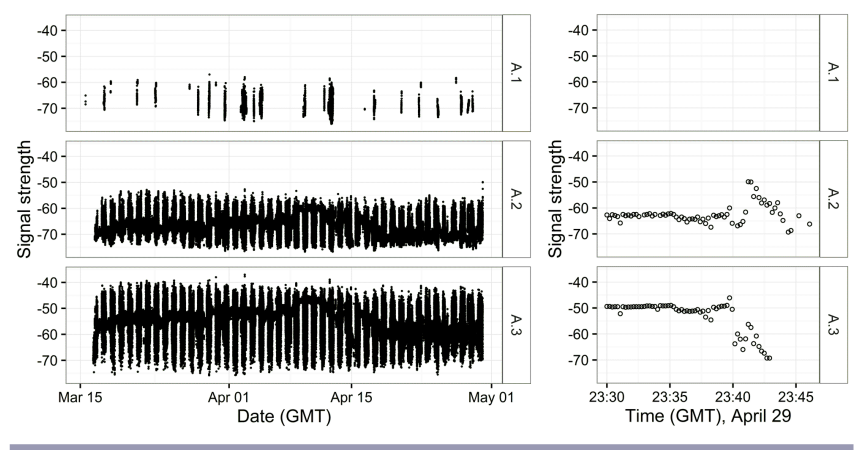

\section{CHALLENGES, OPPORTUNITIES AND FUTURE DIRECTIONS}

Data collected by Motus are filling important knowledge gaps about the movement, biology, and ecology of small migrants at a variety of spatial and temporal scales, while promoting international collaborative research. In particular, Motus excels in applications where continuous detections with high temporal resolution is important, e.g., estimation of flight speeds, fine-scale behavior, or timing of movements, and where an archival tag like a GPS or GLS introduces problematic biases, e.g., one cannot study survival during migration by recapturing only living birds. Complementary to other technologies including stable isotope analyses, archival GPS/GLS, satellite tags, and data loggers, Motus has the potential to play an important role in understanding migratory connectivity and the factors influencing movement and survival throughout the annual life cycle for a wide variety of species.

Since its inception, the spatial expansion of Motus has been fuelled by the dedication, resources, and interest of collaborating 
Fig. 4. Twelve (A-L) Motus stations on which a Swainson's Thrush (Catharus ustulatus), tagged on 16 March 2016 as part of an overwintering study in Colombia, was detected during spring migration (closed red circles; Gonzalez and Hobson, unpublished data). Black circles show the location of Motus stations that were active between 29 April and 31 May 2016, i. e., between the time this individual left its overwintering site (Fig. 3) and passed by the most northern site (L). Red broken lines depict the great circle path between sites, and may not accurately represent the migratory path of this individual. In addition to giving some indication of migratory connectivity, detections collected at sites A-L can provide information on stopover duration, time of departure, time of passage past each site (Figs. 3, 5), and thus derived metrics including ground speed.

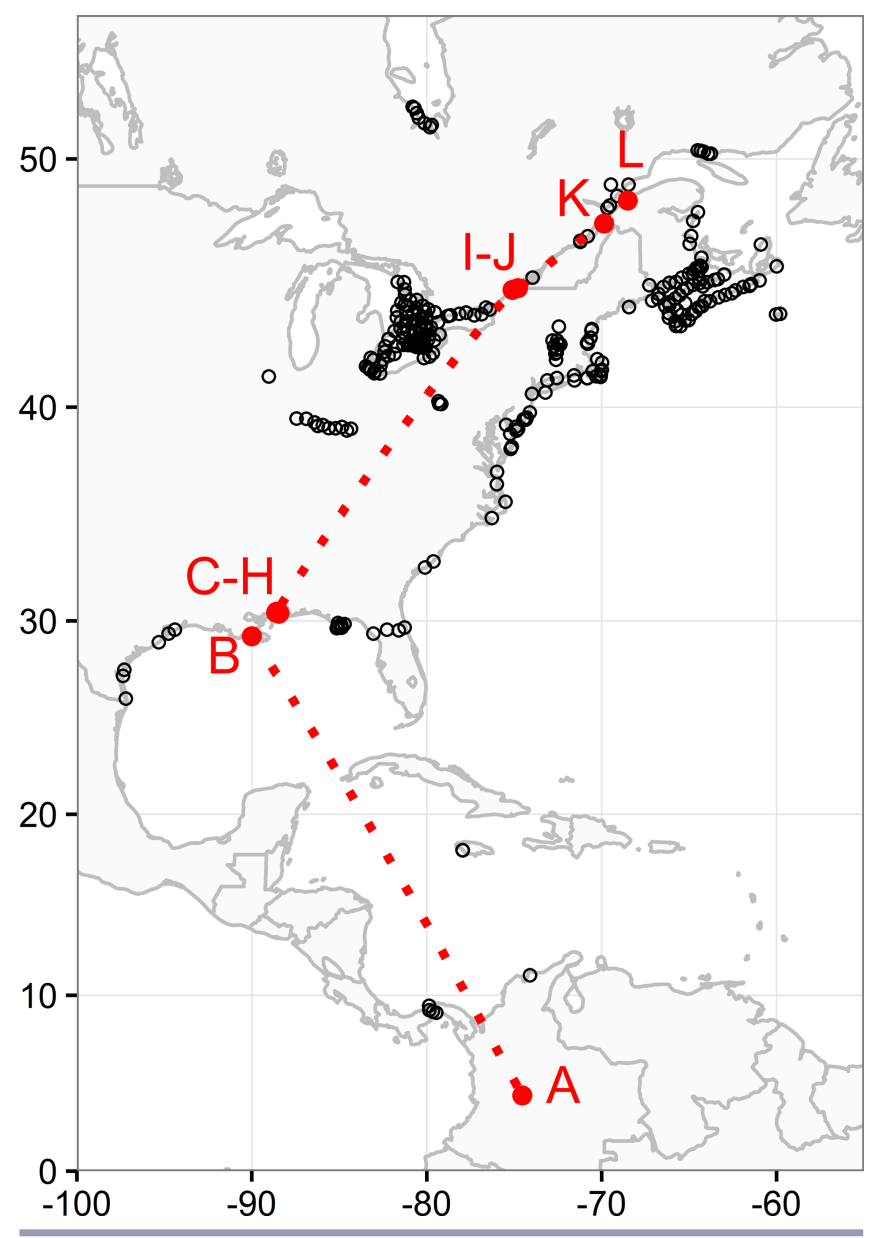

individuals and organizations, interest that has grown largely out of the ability to garner novel movement data for small animals at a spatial and temporal scale that was previously only possible for larger animals. Given the current state of communications and agreements with collaborators, we expect the number of permanent stations to continue to increase, and cover a broader geographic scale. Although this ground-up approach to spatial expansion is expected to remain a key organizing feature of Motus, there is also a need to develop a
Fig. 5. Raw signal strength data for a radio-tagged Swainson's Thrush (Catharus ustulatus) detected at Motus stations C-H, I, $\mathrm{K}$, and L (Fig. 4) after departing on migration from its overwintering site in Colombia on 29 April 2016 (Gonzalez and Hobson, unpublished data). Clear parabolas in signal strength values suggest the individual passed directly through (perpendicular to) the antenna beam, whereas a more consistent signal strength suggests the individual is flying in the same direction as the antenna beam. Signal strength values are not directly comparable between plots on the left and right because data were collected using Lotek receivers on the left, and using Sensorgnome receivers on the right.

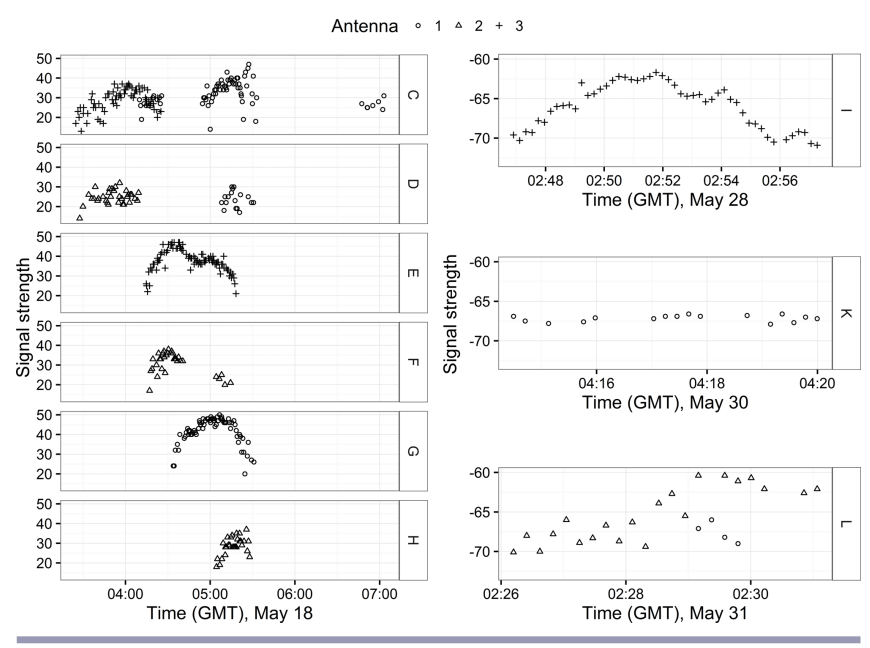

top-down approach to the positioning of stations that will address priority-based research and conservation objectives and fill spatial gaps. Of note are plans to place towers at key migratory bottlenecks, including the Gulf of Mexico coast, throughout the Caribbean and Central America, and at strategic places in South America and Europe. Investments from Motus partners and funders will be required to deploy and maintain permanent stations in priority locations that may not otherwise be covered. Alternative approaches to expansion are also being explored, including the development of home receiver kits that can be purchased and installed by citizen scientists or local naturalist groups at a low cost.

Inconsistent spatial coverage is currently one of the primary factors limiting broad-scale animal movement questions that can be addressed using Motus. Knowledge of migratory behavior obtained from alternative technologies, including GPS, GLS, isotope signatures, and band recoveries can, and is, being used to inform priority areas for targeted Motus projects and subsequent expansion. Likewise, Motus can also complement knowledge obtained from lower resolution position data obtained from GLS, stable isotopes, and band recoveries. For individuals large enough to carry GPS tags, using both GPS and Motus technology together can provide accurate position data with low temporal resolution (GPS) throughout the annual life cycle, and less accurate location data with higher temporal resolution (Motus) in regions with receiving stations, e.g., in the Atlantic arrays (Fig. 1). Combined, these two technologies could provide a comprehensive understanding of postbreeding dispersal and 
migratory routes (GPS and Motus), stopover durations and their approximate locations (Motus), daily activity levels, timing of departure from breeding locations, stopovers, and overwintering locations (GPS and Motus), and for larger species, some data on home-range size during breeding and overwintering periods (GPS). At a smaller spatial scale, manual radio-telemetry can be used in combination with Motus to determine precise locations and to collect observations of animal behavior that could not be derived from Motus data alone, e.g., habitat patch use, foraging habitat and behavior, or prey preference.

Despite the benefits and broad utility of the Motus system, it is important to recognize the limitations of this technology. First, tag life is limiting for some sizes/species; for the smallest organisms capable of carrying a tag $(<10 \mathrm{~g})$, studies are currently limited to a range of 10-90 days depending on the chosen burst rate. Also, only signals that are transmitted within range of a station are recorded, and that range can vary considerably because of environmental and technical factors, some of which are not yet clearly understood. For example, the nature of VHF signals is such that animals in flight are more readily detected (and at much greater ranges) than animals near ground or under the cover of vegetation. More study is needed on the effect of these factors on detectability, and how to incorporate this information into data modeling. Plans are currently underway to double-tag homing pigeons with GPS and coded tags, to estimate detection parameters, including station range and probability of detection when in range, and to assess how our inference of movement parameters (migratory path, speed, and orientation of flight) from Motus compares to reality.

When received, detection data have relatively low geographic resolution compared to GPS technology, although still much higher than GLS. Geographic resolution can be as low as the theoretical range of an antenna, although simultaneous detections on multiple antenna and stations, together with information on signal strength, can allow for more precise estimates of position. Nevertheless, imprecise position data are sufficient to estimate relevant parameters, including diel activity levels, departure timing, orientation, and flight speed. Supplemental manual tracking can be used to produce much more accurate position information for animals on the ground. Further work is needed to determine the configuration and spacing of towers and antennas that optimizes the accuracy and precision of position estimates, and also to develop algorithms to estimate position as accurately as possible through triangulation or other modeling techniques.

There are also challenges associated with maintenance of the receiver network. Automated stations can suffer from unplanned outages due to insufficient power, electronic problems, or weather and other unforeseen circumstances. Therefore, all stations require some level of consistent oversight. Annual maintenance costs need to be taken into consideration when establishing new stations because stations need to be visited regularly to download data and inspect the equipment; costs vary with frequency of visits and remoteness of the station. It is important to emphasize, though, that costs of maintaining the network are considered minimal when compared with the costs of traditional radiotelemetry, which include the cost of staffing field personnel and the inability to collect continuous, high temporal resolution detection data at large spatial scales. Current development of cellular monitoring systems for Sensorgnomes will allow for remote monitoring and control of stations, and our ultimate aim is to fully automate as much of the system as possible.

The Motus database also relies heavily on the accuracy and timeliness of user-provided tag and station metadata, and in turn detection data. These are manageable issues, but do require dedication and discipline from the user community to populate the database with accurate and timely information. To facilitate data providing and access, Motus' central data repository is being designed to alleviate many logistical challenges that researchers may encounter when working with large datasets, including the input, storage, management, and analysis of data (Urbano et al. 2010). In addition to basic visualizations that are publicly available on the web, a user-friendly web-based interface and $\mathrm{R}$ (http://r-project.org) package is being developed that will help Motus users more efficiently manage, summarize and visualize their data. We also anticipate that Motus users will be able to connect their data to Movebank (http://movebank.org) to benefit from their visualization and analysis tools. Combined, these features will allow researchers to more efficiently publish their research and maintain archival copies of their data for future use.

An added-value of the entire system is the collaborative research network itself. With a growing network of collaborating researchers and organizations, there is potential to use the Motus network as ground-based receiving stations to collect data from a variety of tracking technologies outside the current Motus framework. Alternative receivers, or modifications to current receivers, could theoretically be employed by Motus to collect data from any remote-sensing device such as satellite, including the International Cooperation for Animal Research Using Space Initiative (ICARUS) (http://icarusinitiative.org), GPS, and data logging tags with VHF or other means of transmitting data to ground-based stations. Although GPS and satellite technologies are advancing rapidly, there are financial and technical limitations to decreasing the size of tags and to the amount of data that can be stored and transmitted via satellite.

By utilizing a coordinated, collaborative, and international approach to automated radio-telemetry, Motus has broadened the spatial and temporal scale over which small animals can be tracked. To use the Motus network effectively, study objectives need to be clearly defined, and projects planned based on the limitations and reasonable expectations of the technology, including the current spatial configuration of receiving stations. Given that we anticipate continued expansion of the receiver network, the number and breadth of questions that can be addressed using Motus should also expand. For example, with more complete geographic coverage, including strategically placed fences to capture latitudinal movement past migratory bottlenecks, Motus could be used to track longer distance migrations, and complete migrations between overwintering and breeding grounds. Particularly for shorebirds with distinct breeding, stopover, and overwintering sites, migration could conceivably be monitored by receiver stations at each site. Such data could eventually be used to estimate survival and transition parameters during different periods of the life cycle, using traditional mark-recapture methods. Greater spatial coverage will also improve our ability to track short- and long-distance 
dispersal, providing information on survival, breeding success, and, when combined with other demographic or abundance data during stationary periods of the year, factors limiting populations throughout the annual cycle. Given the rapid progress to date and the flexibility of the system for both expansion and linkages with other automated or airborne tracking technologies, we believe that Motus is well positioned to play an important role in solving some of the world's most complex problems in movement ecology well into the future.

Responses to this article can be read online at: http://www.ace-eco.org/issues/responses.php/953

\section{Acknowledgments:}

Motus began as Sensorgnome.org through Acadia University and is now a program of Bird Studies Canada (BSC) in partnership with Acadia University and collaborating researchers and organizations (see https://motus.org/datalpartners.jsp). Motus is indebted to the pioneering work and dedication of J. Brzustowski, lead developer of the SensorGnome (https://sensorgnome.org/, Acadia University). Motus is supported by BSC and collaborating researchers and organizations, CANARIE, Inc., the Government of Canada through Environment and Climate Change Canada and Natural Resources Canada, the Crabtree Foundation, the W. Garfield Weston Foundation, the Ontario Research Fund, the Nova Scotia Research and Innovation Trust, and through the Canada Foundation for Innovation in partnership with Western University, Acadia University, and the University of Guelph. Substantial financial and intellectual contributions to the development of Motus have also been made by the United States Fish and Wildlife Service, Bureau of Ocean Energy Management, Encana Corporation's Deep Panuke Education \& Training and Research \& Development Fund, Natural Sciences and Engineering Research Council of Canada (NSERC) Collaborative Research and Development Grant to PDT, Lotek Wireless, Mitacs, and TD Friends of the Environment Foundation. Many additional individual research partners have made significant contributions to Motus through their own research programs and institutions. Motus would not be possible without the participation of hundreds of landowners and volunteers who host and maintain Motus stations. The writing of this manuscript was supported by a Mitacs Accelerate grant to TLC, in partnership with $B S C$, the University of Western Ontario, and Lotek Wireless, and a NSERC Discovery Grant to PDT. Special thanks to the Colombia thrush research group for use of their data, in particular $A$. M. Gonzalez, K. Hobson, C. Gomez, and N. Bayly. We also thank the collaborators operating stations used in the thrush example: Mississippi State University (S. Rush, J. Fuera, and M. Woodrey), Louisiana Department of Wildlife and Fisheries (M. Seymour), and Université du Québec à Rimouski (M.P. Laplante). The findings and conclusions in this article are those of the author $(s)$ and do not necessarily represent the views of the U.S. Fish and Wildlife Service.

\section{LITERATURE CITED}

Adams, L. 1965. Progress in ecological biotelemetry. BioScience 15:83-86. http://dx.doi.org/10.2307/1293341
Bridge, E. S., K. Thorup, M. S. Bowlin, P. B. Chilson, R. H. Diehl, R. W. Fléron, P. Hartl, R. Kays, J. F. Kelly, W. D. Robinson, and M. Wikelski. 2011. Technology on the move: recent and forthcoming innovations for tracking migratory birds. Bioscience 61:689-698. http://dx.doi.org/10.1525/bio.2011.61.9.7

Brown, J. M., and P. D. Taylor. 2015. Adult and hatch-year Blackpoll Warblers exhibit radically different regional-scale movements during post-fledging dispersal. Biology Letters 11:20150593. http://dx.doi.org/10.1098/rsbl.2015.0593

Cagnacci, F., L. Boitani, R. A. Powell, and M. S. Boyce. 2010. Animal ecology meets GPS-based radiotelemetry: a perfect storm of opportunities and challenges. Philosophical Transactions of the Royal Society of London, Series B, Biological Sciences 365:2157-2162. http://dx.doi.org/10.1098/rstb.2010.0107

Cochran, W. W., D. W. Warner, J. R. Tester, and V. B. Kuechle. 1965. Automatic radio-tracking system for monitoring animal movements. BioScience 15:98-100. http://dx.doi.org/10.2307/1293346

Crysler, Z. 2015. Breeding ground dispersal and fall migratory movements of Ipswich Sparrows (Passerculus Sandwichensis Princeps). Thesis. Acadia University, Wolfville, Nova Sotia, Canada. [online] URL: http://openarchive.acadiau.ca/cdm/ singleitem/collection/Theses/id/1027/rec/5

Crysler, Z. J., R. A. Ronconi, and P. D. Taylor. 2016. Differential fall migratory routes of adult and juvenile Ipswich Sparrows (Passerculus sandwichensis princeps). Movement Ecology 4:3. http://dx.doi.org/10.1186/s40462-016-0067-8

Deppe, J. L., M. P. Ward, R. T. Bolus, R. H. Diehl, A. CelisMurillo, T. J. Zenzal Jr, F. R. Moore, T. J. Benson, J. A. Smolinsky, L. N. Schofield, D. A. Enstrom, E. H. Paxton, G. Bohrer, T. A. Beveroth, A. Raim, R. L. Obringer, D. Delaney, and W. W. Cochran. 2015. Fat, weather, and date affect migratory songbirds' departure decisions, routes, and time it takes to cross the Gulf of Mexico. Proceedings of the National Academy of Sciences of the United States of America 112:E6331-E6338. http://dx.doi. org/10.1073/pnas.1503381112

Dossman, B. C., G. W. Mitchell, D. R. Norris, P. D. Taylor, C. G. Guglielmo, S. N. Matthews, and P. G. Rodewald. 2016. The effects of wind and fuel stores on stopover departure behavior across a migratory barrier. Behavioral Ecology 27:567-574. http://dx.doi. org/10.1093/beheco/arv189

Eikenaar, C., F. Müller, C. Leutgeb, S. Hessler, K. Lebus, P. D. Taylor, and H. Schmaljohann. 2017. Corticosterone and timing of migratory departure in a songbird. Proceedings of the Royal Society B 284(1846). http://dx.doi.org/10.1098/rspb.2016.2300

Falconer, C. M., G. W. Mitchell, P. D. Taylor, and D. C. Tozer. 2016. Prevalence of disjunct roosting in nesting Bank Swallows (Riparia riparia). Wilson Journal of Ornithology 128:429-434. http://dx.doi.org/10.1676/1559-4491-128.2.429

Fraser, K. C., B. J. M. Stutchbury, C. Silverio, P. M. Kramer, J. Barrow, D. Newstead, N. Mickle, B. F. Cousens, J. C. Lee, D. M. Morrison, T. Shaheen, P. Mammenga, K. Applegate, and J. Tautin. 2012. Continent-wide tracking to determine migratory connectivity and tropical habitat associations of a declining aerial insectivore. Proceedings of the Royal Society B 279:4901-4906. http://dx.doi.org/10.1098/rspb.2012.2207 
Fudickar, A. M., M. Wikelski, and J. Partecke. 2012. Tracking migratory songbirds: accuracy of light-level loggers (geolocators) in forest habitats. Methods in Ecology and Evolution 3:47-52. http://dx.doi.org/10.1111/j.2041-210X.2011.00136.x

Goymann, W., F. Spina, A. Ferri, and L. Fusani. 2010. Body fat influences departure from stopover sites in migratory birds: evidence from whole-island telemetry. Biology Letters 6:478-481. http://dx.doi.org/10.1098/rsbl.2009.1028

Hallworth, M. T., and P. P. Marra. 2015. Miniaturized GPS tags identify non-breeding territories of a small breeding migratory songbird. Scientific Reports 5:11069. http://dx.doi.org/10.1038/ srep11069

Hill, I. F., B. H. Cresswell, and R. E. Kenward. 1999. Field testing the suitability of a new back-pack harness for radio-tagging passerines. Journal of Avian Biology 30:135-142. http://dx.doi. org/10.2307/3677122

Kays, R., M. C. Crofoot, W. Jetz, and M. Wikelski. 2015. Terrestrial animal tracking as an eye on life and planet. Science 348(6240). http://dx.doi.org/10.1126/science.aaa2478

Kays, R., S. Tilak, M. Crofoot, T. Fountain, D. Obando, A. Ortega, F. Keummeth, J. Mandel, G. Sweson, T. Lambert, B. Hirsh, and M. Wikelski. 2011. Tracking animal location and activity with an automated radio telemetry system in a tropical rainforest. Computer Journal 54:1931-1948. http://dx.doi. org/10.1093/comjn1/bxr072

Kennedy, L. V., Y. E. Morbey, S. A. Mackenzie, P. D. Taylor, and C. G. Guglielmo. 2016. A field test of the effects of body composition analysis by quantitative magnetic resonance on songbird stopover behaviour. Journal of Ornithology 1-9. http:// dx.doi.org/10.1007/s10336-016-1399-2

Kishkinev, D., D. Heyers, B. K. Woodworth, G. W. Mitchell, K. A. Hobson, and D. R. Norris. 2016. Experienced migratory songbirds do not display goal-ward orientation after release following a cross-continental displacement: an automated telemetry study. Scientific Reports 6:37326. http://dx.doi. org/10.1038/srep37326

Loring, P. H. 2016. Evaluating digital VHF technology to monitor shorebird and seabird use of offshore wind energy areas in the western North Atlantic. Dissertation. University of Massachusetts Amherst, Amherst, Massachusetts, USA.

Louder, M. I. M., M. P. Ward, W. M. Schelsky, M. E. Hauber, and J. P. Hoover. 2015. Out on their own: a test of adult-assisted dispersal in fledgling brood parasites reveals solitary departures from hosts. Animal Behaviour 110:29-37. http://dx.doi. org/10.1016/j.anbehav.2015.09.009

Mann, H. A., D. J. Hamilton, J. M. Paquet, C. L. Gratto-Trevor, and S. G. Neima. 2017. Effects of extreme tidal events on Semipalmated Sandpiper (Calidris pusilla) migratory stopover in the Bay of Fundy, Canada. Waterbirds 40:41-49.

Marra, P. P., D. Hunter and A. M. Perrault. 2011. Migratory connectivity and the conservation of migratory animals. Environmental Law 41:317-354.

McGuire, L. P., C. G. Guglielmo, S. A. Mackenzie, and P. D. Taylor. 2012. Migratory stopover in the long-distance migrant silver-haired bat, Lasionycteris noctivagans. Journal of Animal Ecology 81:377-85. http://dx.doi.org/10.1111/j.1365-2656.2011.01912. $\mathrm{x}$

McGuire, L. P., K. A. Jonasson, and C. G. Guglielmo. 2014. Bats on a budget: torpor-assisted migration saves time and energy. PLoS ONE 9:e115724. http://dx.doi.org/10.1371/journal. pone. 0115724

McKellar, A. E., R. Kenyon Ross, R. I. Guy Morrison, L. J. Niles, R. R. Porter, J. Burger, D. J. Newstead, A. D. Dey, and P. A. Smith. 2015. Shorebird use of western Hudson Bay near the Nelson River during migration, with a focus on Red Knot. Wader Study 122:201-211. http://dx.doi.org/10.18194/ws.00020

McKinnon, E. A., K. C. Fraser, and B. J. M. Stutchbury. 2013. New discoveries in landbird migration using geolocators, and a flight plan for the future. Auk 130:211-222. http://dx.doi. org/10.1525/auk.2013.12226

Mills, A. M., B. G. Thurber, S. A. Mackenzie, and P. D. Taylor. 2011. Passerines use nocturnal flights for landscape-scale movements during migration stopover. Condor 113:597-607. http://dx.doi.org/10.1525/cond.2011.100186

Mitchell, G. W., B. K. Woodworth, P. D. Taylor, and D. R. Norris. 2015. Automated telemetry reveals age specific differences in flight duration and speed are driven by wind conditions in a migratory songbird. Movement Ecology 3:19. http://dx.doi. org/10.1186/s40462-015-0046-5

Müller, F., P. D. Taylor, S. Sjöberg, R. Muheim, A. Tsvey, S. A. Mackenzie, and H. Schmaljohann. 2016. Towards a conceptual framework for explaining variation in nocturnal departure time of songbird migrants. Movement Ecology 4:24. http://dx.doi. org/10.1186/s40462-016-0089-2

Naef-Daenzer, B. 2007. An allometric function to fit leg-loop harnesses to terrestrial birds. Journal of Avian Biology 38:404-407. http://dx.doi.org/10.1111/j.2007.0908-8857.03863.X

Neima, S. G. 2017. Stopover ecology of Semipalmated Sandpipers (Calidris pusilla) during fall migration through the upper Bay of Fundy, Canada. Thesis. Mount Allison University, Sackville, New Brunswick, Canada.

Rakhimberdiev, E., N. R. Senner, M. A. Verhoeven, D. W. Winkler, W. Bouten and T. Piersma. 2016. Comparing inferences of solar geolocation data against high-precision GPS data: annual movements of a double-tagged black-tailed godwit. Journal of Avian Biology 47:589-596. http://dx.doi.org/10.1111/jav.00891

Rappole, J. H., and A. R. Tipton. 1991. New harness design for attachment of radio transmitters to small passerines. Journal of Field Ornithology 62:335-337.

Řeřucha, Š., T. Bartonička, P. Jedlička, M. Čižek, O. Hlouša, R. Lučan, and I. Horáček. 2015. The BAARA (Biological AutomAted RAdiotracking) system: a new approach in ecological field studies. PLOS ONE 10:e116785. http://dx.doi. org/10.1371/journal.pone.0116785

Streby, H. M., T. L. McAllister, S. M. Peterson, G. R. Kramer, J. A. Lehman, and D. E. Anderson. 2015. Minimizing marker mass and handling time when attaching radio-transmitters and geolocators to small songbirds. Condor 117:249-255. http://dx. doi.org/10.1650/CONDOR-14-182.1 
Taylor, P. D., S. A. Mackenzie, B. G. Thurber, A. M. Calvert, A. M. Mills, L. P. McGuire, and C. G. Guglielmo. 2011. Landscape movements of migratory birds and bats reveal an expanded scale of stopover. PloS ONE 6:e27054. http://dx.doi.org/10.1371/ journal.pone.0027054

Urbano, F., F. Cagnacci, C. Calenge, H. Dettki, A. Cameron, and M. Neteler. 2010. Wildlife tracking data management: a new vision. Philosophical Transactions of the Royal Society B 365:2177-2185. http://dx.doi.org/10.1098/rstb.2010.0081

Ward, M. P., M. Alessi, T. J. Benson, and S. J. Chiavacci. 2014. The active nightlife of diurnal birds: extraterritorial forays and nocturnal activity patterns. Animal Behaviour 88:175-184. http:// dx.doi.org/10.1016/j.anbehav.2013.11.024

Warnock, J., and S. Warnock. 1993. Attachment of radiotransmitters to sandpipers: review and methods. Wader Study Group Bulletin 70:28-30.

Woodworth, B. K., C. M. Francis, and P. D. Taylor. 2014. Inland flights of young Red-Eyed Vireos Vireo Olivaceus in relation to survival and habitat in a coastal stopover landscape. Journal of Avian Biology 45:387-395. http://dx.doi.org/10.1111/jav.00276

Woodworth, B. K., G. W. Mitchell, D. R. Norris, C. M. Francis, and P. D. Taylor. 2015. Patterns and correlates of songbird movements at an ecological barrier during autumn migration assessed using landscape-and regional-scale automated radiotelemetry. Ibis 157:326-339. http://dx.doi.org/10.1111/ ibi. 12228 